\title{
Pengaruh Lokasi, Pendapatan Konsumen, Harga Rumah Dan Selera Terhadap Keputusan Pembelian Rumah Bersubsidi Di Kabupaten Manokwari
}

\author{
Noviani Walalayo1, Rumas Alma Yap², Lillyani Margaretha Orisu ${ }^{3}$ \\ ${ }^{1}$ Alumni Jurusan Ekonomi Pembangunan, Universitas Papua \\ ${ }^{2,3}$ Dosen Jurusan Ekonomi Pembangunan, Universitas Papua
}

Received: Agustus 2020; Accepted: September 2020; Published: September 2020

\begin{abstract}
Abstrak
Penelitian ini bertujuan untuk mengetahui pengaruh lokasi, pendapatan konsumen, harga rumah, selera terhadap keputusan pembelian rumah bersubsidi di Kabupaten Manokwari. Adapun variabel dalam penelitian ini adalah Lokasi, Pendapatan Konsumen, Harga Rumah dan Selera. Penelitian ini menggunakan data primer dan data sekunder. Data primer yang didapat melalui kuisioner dan data sekunder didapatkan melalui instansi-instansi terkait penelitian ini, metode analisis yang digunakan adalah dengan menggunakan model regresi linear berganda menggunakan program SPSS Statistic 16. Hasil penelitian secara parsial (uji t) Lokasi, Pendapatan Kosumen, Harga Rumah dan selera berpengaruh positif dan signifikan terhadap keputusan pembelian rumah bersubsidi di Kabupaten Manokwari. Namum secara bersama-sama (simultan) variabel lokasi,pendapatan konsumen, harga rumah dan selera berpengaruh signifikan terhadap keputusan pembelian pada tingkat kepercayaan 95 persen.
\end{abstract}

Kata kunci: lokasi, pendapatan konsumen, harga rumah, selera, keputusan pembelian

\section{Abstract}

This study aims to determine the influence of location, consumer income, house prices, appetite for subsidized home purchase decisions in Manokwari Regency. The variables in this study are Location, Consumer Income, House Price and Taste. This study uses primary data and secondary data. Primary data obtained through questionnaires and secondary data obtained through agencies related to this study, the analysis method used is to use multiple linear regression models using the SPSS Statistic 16 program. The results of the partial study $(t$ test) Location, Kosumen Income, House Prices and tastes had a positive and significant effect on the decision to purchase subsidized homes in Manokwari Regency. But together (simultaneously) variable locations, consumer income, house prices and tastes significantly influenced purchasing decisions at a confidence level of 95 percent.

Keywords: location, consumer income, house prices, tastes, purchasing decisions

How to Cite: Walalayo, N., Yap, Rumas A., Orisu, Lillyani M., (2020). Pengaruh Lokasi, Pendapatan Konsumen, Harga Rumah Dan Selera Terhadap Keputusan Pembelian Rumah Bersubsidi Di Kabupaten Manokwari. JFRES: Journal of Fiscal and Regional Economy Studies, 3 (2), 52 - 58.

\footnotetext{
Corresponding author:

E-mail: r.yap@unipa.ac.id
} 


\section{PENDAHULUAN}

Berbicara tentang perumahan, dalam berbagai wacana pembangunan telah dinyatakan bahwa perumahan adalah salah satu kebutuhan dasar manusia. Ketika wacana tentang kebutuhan beralih ke hak, perumahan pun digolongkan sebagai hak dasar manusia. Meskipun demikian dalam prakteknya di Indonesia perumahan yang lebih banyak dibicarakan sebagai barang dagang. Iklan mengenai perumahan yang lebih banyak menonjolkan gaya dan bentuk rumah banyak mengisi halaman dan acara media.

Rumah menjadi sebuah kebutuhan penting dalam hidup manusia, rumah masuk dalam sebuah lingkar kebutuhan pokok yang setiap orang harus memilikinya. Sebagai salah satu kebutuhan primer bagi hidup manusia, rumah sangat berperan penting dalam keberlangsungan hidup seseorang, rumah tidaklagi hanya sekedar menjadi tempat berlindung pada saat panas dan hujan tetapi berubah menjadi status sosial sang pemilik, karena rumah dimasa kini menjadi gambaran jatidiri, dan karakter seseorang. Dengan demikian rumah sudah menjadi kebutuhan dasar seluruh manusia untuk membina keluarga dalam rangka menjaga kelangsungan kehidupannya. Dari seluruh manusia yang membutuhkan rumah terdapat kelompok yang juga memiliki kesulitan dalam memenuhi kebutuhan perumahan. Kelompok tersebut adalah kelompok masyarakat berpenghasilan rendah.

Menurut Lewis (1984 dalam Suparlan) masyarakat berpenghasilan rendah adalah kelompok masyarakat yang mengalami tekanan ekonomi, social, budaya, dan politik yang cukup lama dan dapat menimbulkan budaya miskin. Menurut Permenpera No. 5/PERMEN/M/2007 masyarakat berpenghasilan rendah adalah masyarakat dengan penghasilan dibawah dua juta lima ratus ribu per bulan.

Karena lemahnya tingkat perekonomian mereka yang menyebabkan lemahnya akses mereka dalam menentukan hidup mereka sendiri. Sebagai solusi menyingkapi permasalahan yang dihadapi oleh masyarakat berpenghasilan rendah pemerintah melalui perbankan merealisasikan pemberian kredit. Salah satu kredit yang diberikan adalah KPR bersubsidi. KPR bersubsidi adalah suatu kredit yang diperuntukan pada masyarakat berpenghasilan rendah (MBR) yang disubsidikan khusus oleh pemerintah bekerja sama dengan Kementrian Pekerjaan Umum dan
Perumahan Rakyat (PUPR) dalam rangka memenuhi kebutuhan perumahan.

Salah satu landasan yang digunakan oleh pemerintah untuk meningkatkan peran kelembagaan dalam pembangunan dan pemukiman adalah Undang-Undang No. 1 Tahun 2011 tentang Perumahan dan Khawasan Pemukiman. "Undang-undang itu menyatakan bahwa perumahan adalah kumpulan rumah sebagai bagian dari pemukiman, baik perkotaan maupun pedesaan, yang dilengkapi dengan prasarana, sarana, dan utilitas umum sebagai hasil upaya pemenuhan rumah yang layak huni Sedangkan pemukiman adalah bagian dari lingkungan hunian yang terdiri atas lebih dari satu satuan perumahan yang mempunyai prasarana, sarana, utilitas umum, serta mempunyai penunjang kegiatan fungsi lain di kawasan perkotaan atau kawasan pedesaan ".

Kebutuhan akan perumahan pada dasarnya dibagi atas dua hal pokok yaitu Kebutuhan akan perumahan berdasarkan tren (kecenderungan) pertumbuhan penduduk secara alamiah serta kebutuhan dan penyediaan rumah berdasarkan atas banyaknya rumah layak huni. Indonesia setiap tahunnya membutuhkan hingga satu juta rumah per tahun. Indonesia membutuhkan jumlah yang semakin besar karena urbanisasi di perkotaan yang meningkat dan merupakan motor pengerak perekonomian yang signifikan. Pemerintah sendiri memberi dukungan untuk kebutuhan perumahan melalui dua skema yaitu melakukan alokasi anggaran langsung melalui Kementrian Pekerjaan Umum dan Perumahan Rakyat (PUPR) serta meningkatkan akses terhadap pembiayaan perumahan.

Sebelumnya pada April 2015 Presiden RI Joko Widodo menetapkan program "Satu Juta Rumah" yang mendapat perhatian sangat besar bagi masyarakat dan khusunya juga bagi pihak swasta/ pengembang untuk membangun perumahan bagi masyarakat berpenghasilan rendah. Selain harganya yang murah terlebih pembayaran rumah bersubsidi ini bisa dilakukan dengan cara kredit atau yang disebut dengan KPR/ Kredit Pemilikan Rumah dengan suku bunga yang ditetapkan. Suku bunga yang ditetapkan hanya 5\% dengan panjang tenor selama 20 tahun, suku bunga tersebut lebih ringan dan mudah dibandingkan dengan suku bunga pada bank komersial yang mencapai $11 \%$ $12 \%$ dengan tenor 8-10 tahun. Program pemerintah ini turut mendorong pihak swasta/pengembang khusunya di Kabupaten 
Manokwari yang kemudian cenderung beralih pada bisnis property (perumahan) karena wilayahnya yang asri serta tingkat pertumbuhan penduduknya yang semakin meningkat.

Tabel 1. Jumlah Penduduk di Kabupaten

Manokwari Tahun 2013-2017

\begin{tabular}{lcr}
\hline Tahun & $\begin{array}{c}\text { Jumlah } \\
\text { Penduduk } \\
\text { (Jiwa) }\end{array}$ & \multicolumn{2}{c}{$\begin{array}{l}\text { Kepadatan } \\
\left.\text { (Jiwa/Km }{ }^{2}\right)\end{array}$} \\
\hline 2013 & 79.776 & 47.13 \\
\hline 2014 & 81.911 & 48.43 \\
\hline 2015 & 83.980 & 49.69 \\
\hline 2016 & 86.321 & 51.02 \\
\hline 2017 & 88.526 & 52.34 \\
\hline Sumber BPS Provinsi Papua Barat, 2017 & \\
\hline
\end{tabular}

Jumlah penduduk di Kabupaten Manokwari pada tahun 2013 adalah 79.776 jiwa, pada tahun 2014 jumlah penduduk di Kabupaten Manokwari meningkat menjadi 81.911 jiwa. Pada tahun 2015 meningkat 83.980 jiwa dan pada tahun 2016 dan 2017 meningkat secara segnifikan menjadi 86.312 jiwa dan 88.525 jiwa. Sehingga disimpulkan bahwa di Kabupaten Manokwari pada setiap tahunnya mengalami peningkatan jumlah penduduk.

Pesatnya pertumbuhan penduduk di Kabupaten Manokwari tidak bisa lepas dari semakin strategisnya Manokwari baik secara ekonomi maupun politisi. Dengan adanya peningkatan pertumbuhan penduduk dari tahun ke tahun yang terjadi di Kabupaten Manokwari, menunjukan bahwa kebutuhan akan perumahan sangatlah penting. Peningkatan ini mendorong pihak swasta/ pengembang untuk berlomba-lomba mengembangkan usaha property di bidang perumahan.

Tabel 2. Daftar Nama Perumahan Bersubsidi Di Kabupaten Manokwari

\begin{tabular}{|c|c|c|c|c|}
\hline No & Nama Perumahan & Bank Yang Bekerja Sama & Pengembang & Lokasi \\
\hline 1 & Sogun Permai 1 & BTN,Bank Papua, BRI, BNI & PT. FullicaLand & Jln. Drs. Esau Sesa \\
\hline 2 & Sogun Permai 2 & BTN,Bank Papua,BRI, BNI & PT. FullicaLand & Jln. Drs.Esau Sesa \\
\hline 3 & Sogun Permai 5 & BTN,Bank Papua,BRI, BNI & PT.FullicaLand & Jln. Drs. Esau Sesa \\
\hline 4 & Griya Anday & BTN,Bank Papua,BRI, BNI & PT. FullicaLand & Anday \\
\hline 5 & Amban Hill 2 & Bank Papua dan BTN & PT. Irman Jaya Martabe & Jln. Tugu Jepang Amban \\
\hline 6 & Soribo Permai & Bank Papua dan BTN & PT. Irman Jaya Martabe & $\begin{array}{l}\text { Jln. Kampung Thomas } \\
\text { Soribo }\end{array}$ \\
\hline 7 & Hamawi Permai & Bank Papua dan BTN & PT. Irman Jaya Martabe & $\begin{array}{l}\text { Jln. Poros Ransiki Kab. } \\
\text { Manokwari Selatan }\end{array}$ \\
\hline 8 & Arfai Indah & Bank Papua dan BTN & PT. Indah Asri Persada & Jln. Trikora Anday \\
\hline 9 & $\begin{array}{l}\text { Anggory Persada } \\
\text { Regency }\end{array}$ & Bank Papua dan BTN & PT. Indah Asri Persada & $\begin{array}{l}\text { Jln. Litbang Anggori, } \\
\text { Amban }\end{array}$ \\
\hline 10 & Arfai Salak & Bank Papua dan BTN & PT. Indah Asri Persada & Jln. Trikora Anday \\
\hline 11 & Puncak Arfai Permai & Bank BNI dan BTN & $\begin{array}{l}\text { PT.Gunung Meja dan PT. } \\
\text { Matriecs Cipta Anugerah }\end{array}$ & $\begin{array}{l}\text { Jln.TPA Kampung } \\
\text { Masyepi }\end{array}$ \\
\hline 12 & Amban Pantai Permai & Bank BTN & PT. Bangsawan Sejati & Amban Pantai \\
\hline 13 & Griya Permata Sowi & Bank BTN & PT. Graha Arfak Sejati & $\begin{array}{l}\text { Jln.TPA Kampung } \\
\text { Masyepi }\end{array}$ \\
\hline 14 & Griya Swapen Indah & Bank BNI & PT. Trikora Bangun Papua & Jln. Swapen Bahari \\
\hline 15 & Ingramui Res & Bank BNI & PT. Trikora Bangun Papua & $\begin{array}{l}\text { Kampung Ingramui } \\
\text { Lembah Hijau }\end{array}$ \\
\hline 16 & Green Valey & Bank BNI & PT. Trikora Bangun Papua & $\begin{array}{l}\text { Jln. Pertanian Lembah } \\
\text { Hijau }\end{array}$ \\
\hline 17 & Pesona Anggori & Bank Papua & PT. Binar Tri Sakti & Jln. Amban Pantai \\
\hline 18 & Green City Maripi & Bank Papua & PT. Binar Tri Sakti & Jln. Trikora Maripi \\
\hline 19 & Griya Prafi Indah & Bank Papua & PT. Binar Tri Sakti & Jln. Poros SP 2 Prafi \\
\hline 20 & Griya Manggoapi & Bank Papua & PT. Binar Tri Sakti & Jln. Manggoapi Amban \\
\hline 21 & Beringin Hills & Bank Papua & PT. Sinar Momi Waren & $\begin{array}{l}\text { Jln. Transat Kampung } \\
\text { Wailuri }\end{array}$ \\
\hline 22 & Soribo Hills & Bank BTN & PT. Gunung Hermon & Soribo kampung andagau \\
\hline 23 & $\begin{array}{l}\text { Alamanda Sowi } \\
\text { Gunung }\end{array}$ & Bank BTN & PT. Mahaputra Indi Kusuma & Sowi Gunung \\
\hline
\end{tabular}

\section{Sumber: Data Primer, 2018}

Pertumbuhan perusahan property ternyata tak hanya terjadi di kota-kota besar dipulau jawa, tetapi juga menyebar di seluruh nusantara tak terkecuali Provinsi Papua Barat khususnya Kabupaten Manokwari. Dengan berkembangnya perusahaan property di Kabupaten Manokwari turut membantu program pemerintah dalam hal 
pengadaan rumah dengan harga yang terjangkau fasilitas yang cukup dan lokasi yang strategis. Fenomena seperti ini dapat menjadi ancaman karena makin banyak pesaing maka akan semakin memperketat intensitas persaingan. dimana persaingan akan timbul dari perusahaan property mengingat produk yang ditawarkan merupakan bagian dari program pemerintah yang harus dijalankan.

Permintaan konsumen akan perumahan dipengaruhi oleh beberapa faktor diantaranya lokasi, pendapatan konsumen, harga rumah, pertambahan penduduk, kemudahan mendapat pinjaman, fasilitas dan sarana umum, dan peraturan perundangan. Salah satu faktor yang juga berpengaruh yaitu selera konsumen. Selera merupakan kegiatan seseorang untuk membeli suatu barang atas jasa. Selera pada umumnya berubah dari waktu ke waktu.

\section{METODE PENELITIAN}

Populasi dalam penelitian ini adalah 19.612,4 jiwa kepala keluarga yang tinggal di Distrik Manokwari Barat dan Distrik Manokwari Timur. Sampel dalam penelitian ini berjumlah 50 responden. Menurut Hair (2006) menyatakan bahwa data yang diolah dengan regresi linear berganda memiliki jumlah sampel minimal 50 responden dan lebih di sarankan 100 responden bagi kebanyakan situasi.

Metode pengumpulan data dalam penelitian ini didapatkan melalui penyebaran kuisioner dan studi Pustaka. Kuesioner adalah daftar pertanyaan tertulis yang dirumuskan sebelumnya yang akan dijawab oleh responden dengan menggunakan alternatif jawaban (Sekaran, 2016). Sedangkan Studi Pustaka yaitu teknik pengumpulan data dan informasi dengan melakukan kegiatan keperpustakaan melalui buku-buku, jurnal dan sebagainya yang berkaitan dengan tujuan penelitian (Sugiyono,2013)

Alat analisis yang digunakan pada penelitian ini adalah analisis regresi linear berganda. Analisis regresi linear berganda dilakukan untuk menguji pengaruh dua atau lebih variabel independen terhadap satu variabel dependen. Persamaan regresi berganda adalah sebagai berikut:

$Y=a+\beta_{1} X_{1}+\beta_{2} X_{2}+\beta_{3} X_{3}+\beta_{4} X_{4}+e$

Keterangan:

$\mathrm{Y}=$ Keputusan pembelian (variabel dependent)

$\mathrm{a}=$ Konstanta

$\beta \mathrm{i}=$ Koefisien regresi
$\mathrm{X} 1=$ Lokasi

$\mathrm{X} 2=$ Pendapatan konsumen

$\mathrm{X} 3=$ Harga rumah

$\mathrm{X} 4=$ Selera

$\mathrm{e}=$ Standar Eror

\section{HASIL DAN PEMBAHASAN}

Sampel awal dari penelitian ini adalah menggunakan 50 responden. Karakteristik responden yang berkaitan dengan keputusan pembelian meliputi lokasi, pendapatan konsumen, harga rumah dan selera. Adapun karakteristik responden secara umum berdasarkan jenis kelamin, usia, tingkat pendidikan, jumlah anggota keluarga dan jumlah pendapatan.

Diketahui bahwa dari 50 responden penelitian, menunjukan bahwa 24 responden atau $48 \%$ berjenis kelamin laki-laki dan 26 responden atau $52 \%$ berjenis kelamin perempuan. Hal ini menunjukan bahwa sebagian besar responden berjenis kelamin perempuan yang berjumlah 26 responden atau $52 \%$. Dari 50 responden atau $70 \%$ berada pada usia 24-40 tahun sedangkan 15 responden atau $30 \%$ berada pada usia $>41$ tahun. Hal ini menunjukan bahwa sebagian besar responden memiliki usia yang berkisar 24-40 tahun yang berjumlah 35 atau $70 \%$.

Selanjutnya, 19 responden atau $38 \%$ memiliki pendidikan terakhir pada jenjang SMA, kemudian 4 responden atau 8\% memiliki pendidikan terakhir pada jenjang D3, dan yang terakhir yaitu 27 responden atau 54\% memiliki pendidikan terakhir pada jenjang S1. Hal ini menunjukan bahwa sebagian besar responden memiliki pendidikan terakhir pada jenjang S1 yang berjumlah 27 responden atau $54 \%$.

Dari 50 responden penelitian, menunjukan bahwa pendapatan yang diterima oleh masyarakat yang tinggal pada wilayah Manokwari Timur dan Manokwari Barat adalah 1.000.000 - 5.000.000 sebanyak 44 responden, sedangkan untuk > 5.000.000 sebanyak 6 responden atau 12\%. Hal ini menunjukan bahwa sebagian besar responden memiliki pendapatan sebesar 1.000.0005.000.000 yang berjumlah 44 responden atau $88 \%$. Dari 50 responden penelitian ini, yang menunjukan bahwa jenis pekerjaan masyarakat di wilayah Manokwari Timur dan di wilayah Manokwari Barat beragam dimana masyarakat dengan pekerjaan sebagai PNS sebanyak 20 responden atau $40 \%$ masyarakat dengan pekerjaan sebagai hononer dan swasta masing- 
masing sebanyak 16 dan 13 responden atau $32 \%$ dan $26 \%$ sedangkan sebagai TNI sebanyak 1 responden atau $2 \%$. Hal ini menunjukan bahwa sebagian besar responden adalah PNS yang berjumlah 20 responden atau $40 \%$.
Analisis regresi linear berganda yang telah dilakukan diperoleh koefisien regresi seperti yang dapat dilihat pada tabel 3 .

Tabel 3. Hasil Regresi Linear Berganda

\begin{tabular}{lrrrrr}
\hline \multirow{2}{*}{ Model } & \multicolumn{2}{c}{ Unstandardized Coefficients } & $\begin{array}{c}\text { Standardized } \\
\text { Coefficients } \\
\text { Beta }\end{array}$ & t & Sig. \\
\cline { 2 - 5 } & $\mathbf{B}$ & Std. Error & & 2.624 & 0.012 \\
\hline (Constant) & 9.241 & 3.522 & 0.301 & 2.057 & 0.003 \\
\hline $\mathbf{X 1}$ & 0.225 & 0.109 & 0.017 & 2.127 & 0.001 \\
\hline $\mathbf{X 2}$ & 0.021 & 0.167 & 0.054 & 2.338 & 0.004 \\
\hline $\mathbf{X 3}$ & 0.049 & 0.146 & 0.392 & 2.917 & 0.005 \\
\hline $\mathbf{X} 4$ & 0.44 & 0.151 & & & \\
\hline
\end{tabular}

\section{Sumber: Data Primer Diolah, 2019}

Dari tabel 3 apabila ditulis dalam bentuk persamaan regresi linear berganda adalah sebagai berikut:

$\mathrm{Y}=9.241+0,225+0,021+0,049+0,440+\mathrm{e}$

Nilai konstanta sebesar 9.241. Hal ini berarti jika variable-variabel yang digunakan untuk mengukur Lokasi (X1), Pendapatan konsumen (X2), Harga rumah (X3), dan Selera (X4) diangap konstan, maka keputusan pembelian (Y) nilainya adalah 9.241.

Koefisien regresi variable Lokasi (X1) sebesar 0,225 dan mempunyai nilai yang positif. Hal ini menunjukan bahwa lokasi berpengaruh positif terhadap keputusan pembelian secara signifikan. Yang artinya bahwa apabila lokasi naik sebesar satu persen maka keputusan pembelian akan meningkat sebesar $0,225 \%$. Sejalan dengan yang di jelaskan oleh Awang (1997) yaitu semakin baik lokasi perumahan apakah dipusat kota atau dipinggir kota sangat mempengaruhi keputusan konsumen dalam membeli rumah tersebut.

Koefisien regresi variable Pendapatan konsumen (X2) sebesar 0,021 dan mempunyai nilai yang positif. Hal ini menunjukan bahwa pendapatan konsumen berpengaruh positif terhadap keputusan pembelian secara signifikan. Yang artinya bahwa apabila pendapatan konsumen naik sebesar satu persen maka keputusan pembelian akan meningkat sebesar $0,021 \%$. Hal ini disebabkan karena kesanggupan seseorang di dalam memiliki rumah sangat dipengaruhi pendapatan yang diperolehnya. Hal ini sejalan dengan penelitian menurut Widiastuti (2017) yang mengemukakan bahwa pendapatan konsumen berpengaruh positif dan signifikan terhadap keputusan pembelian rumah bersubsidi.
Koefisien regresi variable Harga rumah (X3) sebesar 0,049 dan mempunyai nilai yang positif. Hal ini menunjukan bahwa harga rumah berpengaruh positif terhadap keputusan pembelian secara signifikan. Yang artinya bahwa apabila harga rumah naik sebesar satu persen maka keputusan pembelian akan meningkat sebesar 0,049 \%. Seperti pendapat Hermawan (2002) yang menyatakan bahwa harga rumah adalah sesuatu yang dipresepsikan oleh konsumen, semakin baik presepsi konsumen terhadap harga produk menunjukan adanya maksimalisasi fungsi atau kegunaan dari barang tersebut.

Koefisien regresi variable Selera (X4) sebesar 0,440 mempunyai nilai yang positif. Hal ini menunjukan bahwa selera berpengaruh positif terhadap keputusan pembelian secara signifikan. Yang artinya apabila selera naik sebesar satu persen maka keputusan pembelian akan meningkat sebesar $0,440 \%$. Selera seseorang sendiri dapat berubah dari waktu ke waktu. Sejalan dengan pendapat dari Kotler (2005) yang mengemukakan bahwa meningkatkan selera seseorang terhadap suatu barang pada umumnya berakibat naiknya jumlah permintaan terhadap barang barang tersebut begitu pula sebaliknya menurunnya selera seseorang terhadap suatu barang tertentu pada umumnya berakibat berkurangnya jumlah permintaan terhadap barang tersebut. Oleh karena itu perusahaan harus dapat mengahsilkan suatu produk yang sesuai dengan selera konsumen.

Dilihat dalam tabel 4 nilai t hitung untuk variabel Lokasi (X1) yaitu 2,057 dan nilai signifikan lebih kecil dari probabilitas 0,05 atau $0,003<0,05$ maka $\mathrm{H}_{0}$ ditolak dan $\mathrm{H}_{1}$ diterima. Hal ini berarti lokasi berpengaruh secara signifikan terhadap 
keputusan pembelian atau dengan kata lain lokasi mempengaruhi keputusan pembelian rumah bersubsidi di Kabupaten Manokwari. Hal ini sejalan dengan penelitian yang dilakukan oleh Erni Widiastuti (2017) yang menyatakan bahwa ada pengaruh positif dan signifikan antara factor lokasi baik secara pasrial maupun simultan terhadap keputusan pembelian.

\begin{tabular}{lcc}
\multicolumn{1}{c}{ Tabel 4. Hasil Uji Parsial (Uji t) } \\
\hline \multicolumn{1}{c}{ Model } & T & Sig \\
\hline (Constant) & 2.624 & 0.012 \\
\hline Lokasi(X1) & 2.057 & 0.003 \\
\hline $\begin{array}{l}\text { Pendapatan } \\
\text { Konsumen(X2) }\end{array}$ & 2.127 & 0.001 \\
\hline Harga Rumah (X3) & 2.338 & 0.004 \\
\hline Selera (X4) & 2,917 & 0.005
\end{tabular}

Sumber : Data Primer Diolah, 2019

Selanjutnya, nilai $\mathrm{t}$ hitung untuk variabel pendapatan konsumen (X2) yaitu 2.127 nilai ini signifikan atau lebih kecil dari probabilitas 0,05 atau $0,001<0,05$ maka $\mathrm{H}_{0}$ ditolak dan $\mathrm{H}_{1}$ diterima. Hal ini berarti pendapatan konsumen berpengaruh secara signifikan terhadap keputusan pembelian atau dengan kata lain pendapatan konsumen mempengarui keputusan pembelian rumah bersubsidi di Kabupaten Manokwari. Hal ini sejalan dengan penelitian yang dilakukan oleh Widiastuti (2017) yang menyatakan bahwa ada pengaruh positif dan signifikan antara factor pendapatan konsumen baik secara pasrial maupun simultan terhadap keputusan pembelian.

Nilai t hitung untuk variabel harga rumah (X3) yaitu 2.338 nilai ini signifikan atau lebih kecil dari probabilitas 0,05 atau $0,004<0,05$ maka $\mathrm{H}_{0}$ ditolak dan $\mathrm{H}_{1}$ diterima. Hal ini berarti harga rumah berpengaruh secara signifkan terhadap keputusan pembelian rumah atau dengan kata lain harga rumah mempengaruhi keputusan pembelian rumah bersubsidi di Kabupaten Manokwari. Hal ini sejalan dengan penelitian yang dilakukan oleh Widiastuti (2017) yang menyatakan bahwa ada pengaruh positif dan signifikan antara factor harga rumah baik secara pasrial maupun simultan terhadap keputusan pembelian.

Dilihat dari tabel 4, nilai t hitung untuk variabel selera (X4) yaitu 2,917 nilai ini signifikan atau lebih kecil dari probabilitas 0,05 atau 0,005 < 0,05 maka $\mathrm{H}_{0}$ ditolak dan $\mathrm{H}_{1}$ diterima. Hal ini berarti selera berpengaruh secara signifikan terhadap keputusan pembelian rumah atau dengan kata lain harga rumah mempengaruhi keputusan pembelian rumah bersubsidi di Kabupaten Manokwari.

Tabel 5. Hasil Uji Koefisien Determinasi $\left(\mathrm{R}^{2}\right)$

\begin{tabular}{ccrr}
\hline $\mathbf{R}$ & $\begin{array}{c}\mathbf{R} \\
\text { Square }\end{array}$ & $\begin{array}{c}\text { Adjusted } \\
\mathbf{R} \\
\text { Square }\end{array}$ & $\begin{array}{c}\text { Std. Error } \\
\text { of the } \\
\text { Estimate }\end{array}$ \\
\hline $0.550 \mathrm{a}$ & 0.303 & 0.257 & 2.143 \\
\hline
\end{tabular}

\section{Sumber : Data Primer Diolah, 2019}

Berdasarkan tabel 5 angka $\mathrm{R}^{2}$ (R-square) sebesar 0,303 atau $30,3 \%$. Hal ini menunjukan bahwa presentase sumbangan pengaruh variabel independen (loaksi,pendapatan konsumen,harga rumah dan selera) terhadap variabel dependen (keputusan pembelian) sebesar 30,3\% sisanya sebesar $69,7 \%$ dipengaruhi oleh variabel-variabel lain diluar model yang tidak diteliti dalam penelitian ini.

\section{KESIMPULAN}

Berdasarkan hasil pengujian dan pembahasan, maka dapat diambil kesimpulan sebagai berikut:

1. Faktor lokasi, pendapatan kosumen, harga rumah dan selera secara bersama-sama berpengaruh positif terhadap keputusan pembelian rumah bersubsidi dengan persamaan: $\mathrm{Y}=9.241+0.225+0.021+0.049$ $+0.040+$ e pada tingkat signifikan 0,05 dan $\mathrm{R}^{2}=0,303$.

2. Lokasi, pendapatan kosumen, harga rumah dan selera berpengaruh positif terhadap keputusan pembelian rumah bersubsidi pada taraf signifikan 0,05.

\section{DAFTAR PUSTAKA}

Badan Pusat Statistik (BPS) Kabupaten Manokwari, 2015 Manokwari Dalam Angka.

Hair. 2006. Multivariate Data Analysis, Fifth Edition. New Jersey. Prentice Hall.

Peraturan Menteri Negara Perumahan Rakyat Nomor: 05/Permen/M/2007 Tentang Pengadaan Perumahan Dan Permukiman Dengan Dukungan Fasilitas Subsidi Perumahan Melalui Kprs/Kprs Mikro Bersubsidi. http://jdih.mkri.id.

Sugiyono, 2013. Metode Penelitian Kuantitatif, Kualitatif, dan R\&D.Bandung: Alfabeta Bandung. 
Suparlan, Pasurdi. 1984. Kebudayaan Kemiskinan dalam Buku Kemiskinan Perkotaan. Jakarta. Penerbit Sinar Harapan.

Undang-Undang No. 1 Tahun 2011 tentang Perumahan dan KawasanPermukiman. https://www.bphn.go.id.

Widiastuti, Erni dan Handayani, SWE. 2017. Analisis Faktor-Faktor Yang Mempengaruhi Keputusan Pembelian Rumah Bersubsidi Dengan Menggunakan Analisis Regresi. Universitas Surakarta 